\title{
A linguagem visual da Bíblia de Família Pictorial de Foster do ano 1890 e a articulação do afeto religioso e da sensibilidade social
}

\section{The visual language of Foster's Family Pictorial Bible from 1890, and its articulation of religious affection and social sensitivity}

\section{El lengua visual de la Bíblia de Família Pictorial de Foster del ano 1890 y la articulación del afecto religioso y de la sensibilidad social}

\author{
Helmut Renders \\ Lidia Kameyo Ueda-Fischer
}

\begin{abstract}
RESUMO
Este artigo investiga a linguagem visual da Pictorial Family Bible de John Foster do ano 1890, trazida para o Brasil por um missionário da Igreja Metodista Episcopal, Sul, apesar de ter sido criada na cidade de Filadélfia do estado de Pensilvânia, historicamente dedicada às lutas sociais, inclusive, dos afro-descentes estadunidenses. Propõe-se de investigar a linguagem visual dessa Bíblia, pela identificação de artistas, temas e estilos para sua melhor contextualização. O método se inspira na análise iconográfica e interpretação iconológica de Erwin Panofsky. Conclua-se que elementos como o tema da capa, o acréscimo do termo de compromisso de temperança e a opção preferencial pelo artista Gustave Doré e seu estilo romântico sob consideração dos temas da sua obra como toda compõem uma narrativa visual de uma religiosidade afetiva, de uma noção da vulnerabilidade humana e de uma sensibilidade social típica para o movimento do Evangelho Social.

Palavras-chaves: Linguagens religiosas; cultura visual evangélica; Igreja Metodista Episcopal do Sul; cultura visual evangélica brasileira; Evangelho Social.
\end{abstract}

\begin{abstract}
This article investigates the visual language of John Foster's Pictorial Family Bible from the year 1890, brought to Brazil by a missionary from the Methodist Episcopal Church, South, despite having been created in the city of Philadelphia in the state of Pennsylvania, a place historically dedicated to social struggles, including those of American Afro-descendants. It is proposed to investigate the visual language of this Bible, by identifying artists, themes and styles for its better contextualization. The method is inspired by Erwin Panofsky's iconographic analysis and iconological interpretation. It is concluded that elements such as the cover theme, the addition of the temperance commitment term and the preferred option by the artist Gustave Doré and his romantic style under consideration of the themes of his work as a whole make up a visual narrative of an affective religiosity, of a notion of human vulnerability and a typical social sensitivity for the movement of the Social Gospel. Keywords: Religious languages; evangelical visual culture; Southern Episcopal Methodist Church; Brazilian evangelical visual culture; Social Gospel.
\end{abstract}




\begin{abstract}
RESUMEN
Este artículo investiga el lenguaje visual de la Pictorial Family Bible de John Foster del año 1890, traída a Brasil por un misionero de la Iglesia Metodista Episcopal del Sur, a pesar de haber sido criada en la ciudad de Filadelfia en el estado de Pennsylvania, históricamente dedicada a luchas sociales, incluidas las de los afrodescendientes estadounidenses. Se propone investigar el lenguaje visual de esta Biblia, identificando artistas, temas y estilos para su mejor contextualización. El método está inspirado en el análisis iconográfico y la interpretación iconológica de Erwin Panofsky. Se concluye que elementos como el tema de la capa del libro, la adición del término de compromiso de templanza y la opción preferida por el artista Gustave Doré, su estilo romántico bajo la consideración de los temas de su obra en su conjunto conforman una narrativa visual de una religiosidad afectiva, de una noción de vulnerabilidad humana y una sensibilidad social típica para el movimiento del Evangelio Social. Palabras claves: Lenguas religiosas; cultura visual evangélica; Iglesia Metodista Episcopal del Sur; cultura visual evangélica brasileña; evangelio social.
\end{abstract}

\title{
Introdução
}

O estudo do surgimento da cultura visual evangélica brasileira representa um desafio, especialmente quando se refere às igrejas do protestantismo de missão, como a Igreja Batista, a Igreja Congregacional, a Igreja Metodista e a[s] Igreja[s] Presbiteriana[s]. Trata-se de um desafio, porque não há estudos abrangentes e detalhados, que correspondam às pesquisas feitas, por exemplo, por David Morgan referente à cultura visual protestante estadunidense dos séculos 19 e 20, e, isso, tanto em relação a um inventário de possíveis objetos de pesquisa quanto a respeito dos métodos adequados aos estudos destes objetos.

Em seguida, propomos avançar nas duas direções e apresentar um primeiro estudo da linguagem visual de uma Bíblia da Família Pictorial evangélica que circulou no Brasil, ${ }^{1}$ sob consideração do material visual e de temas articulados especialmente pela arte religiosa, da escolha preferencial de artistas e da sua pertença a escolas ou vertentes de arte; sob a consideração da sua obra geral na procura de correspondências com o mundo religioso da época. Como método, inspiramo-nos na metodologia iconológica de Erwin Panofsky, em especial seus passos da análise iconográfica e interpretação iconológica.

\section{A Bíblia de Família Pictorial de Foster como exemplo de um gênero da cultura visual evangélica}

Quando a Bíblia de Família Pictorial de Foster, impressa em $1890,{ }^{2}$ chega no Brasil, ela faz parte de um gênero próprio e legítimo da cultura visual evangélica estadunidense bem estabelecida. Ele forma um subgênero da

\footnotetext{
1 O artigo apresenta resultados parciais do projeto regular de pesquisa FAPESP processo 2015/13737-7 [vigência 09-2017-08-2019] de Helmut Renders e do projeto FAPESP de iniciação científica processo 2018/18803-6 [vigência 01-2019 a 12-2019], de Lidia Kameyo Ueda, orientada pelo prof. Helmut Renders.

2 A sua primeira edição era de 1874 .
} 
cultura visual protestante estadunidense como fusão conceitual das Bíblias de Casa alemãs (Hausbibeln), das Bíblias ilustradas e das Bíblias de família inglesas ${ }^{3}$ (cf. RENDERS, 2018, p. 100-127). A primeira edição completa de uma bíblia da família ilustrada nos Estados Unidos da América foi A Nova e Iluminada Bíblia Pictorial com cerca de 400 imagens, de James Harper (1795-1869), publicada entre 1843 e 1846 em cadernos. Harper era metodista de berço, ou seja, pertencia a uma igreja "da missão" que operava, posteriormente, no Brasil. ${ }^{4}$ Quando a edição de Harper, lançado originalmente em 1875, chega no Brasil, esse gênero já tinha encantado mais do que 40 anos as famílias estadunidenses e era bem aceito e estabelecido como parte da cultura visual evangélica estadunidense. Eram objetos de prestigioso e ferramentas de estudo que exemplificaram como a cultura visual evangélica tinha chegada no centro das igrejas e das famílias das suas membresias.

\section{Motivos, temas e artistas da cultura visual da Bíblia de Família Pictorial de Foster}

A Bíblia de Família Pictorial de Foster contém o seguinte material visual:

- Uma página colorida numa das primeiras folhas internas;

- 18 ilustrações em preto branco, cada uma de uma página inteira, distribuídas ao longo dos textos do Antigo e do Novo Testamento;

- Um termo de compromisso, nominalmente, de temperança, praticamente, porém, de abstinência do consumo de álcool, com motivos visuais e ornamentações, breves títulos ou textos e espaços para o preenchimento para os membros da família.

Em termos mais formais, compartilham a "capa" colorida e o "Termo de temperança" uma linguagem visual mais próxima e, ao mesmo, não plenamente idêntica, mas, certamente, distinta da linguagem visual das imagens interiores. Se isso poderia até ser entendida como a formação de uma moldura "temática" iremos discutir mais adiante.

Observe-se, além disso, que em comparação com outras bíblias ilustradas, por exemplo, a tradução da Vulgata ilustrada por Gustave Doré com mais do que 800 imagens ou, a Bíblia ilustrada de Harper, com mais do que 400 imagens, o número de imagens não é alto. Entretanto, isso não significa que essa linguagem visual não seja uma consciente sinalização ou

\footnotetext{
A primeira "bíblia de família" alemã, não aparece antes do ano de 1832 (RAUER).

O engajamento do campo da cultura visual para a promoção do evangelho não era incomum entre os metodistas e se estendeu até os esforços publicitários de Samuel Wesley (1662-1735), pai de John Wesley (1703-1791). Ele publicou durante a sua vida, uma obra em três volumes com poesias e gravuras de partes do Antigo (WESLEY, 1716 e 1723 e do Novo Testamento (WESLEY, 1701), com um total de 485 gravuras.
} 
orientação visual promovendo uma leitura do próprio texto "sagrado" em prol de uma praxis pietatis específica.

A capa interna colorida da Bíblia de Familia Pictorial de Foster, on a apresentação do seu projeto programático

A capa policromática é composta por diversas narrativas imagéticas e textuais, inclusive do primeiro e segundo testamento da Bíblia cristã. A sua composição é clara e pode ser dividida em dois ou em três círculos (fig. 1 e 2 [seções $2 \mathrm{~B}+1 \mathrm{~B}$ ]) em três seções verticais (fig. 2 [seções $1 \mathrm{~A}$ - 1C; $2 \mathrm{~A}$ - 2C; $3 \mathrm{~A}-3 \mathrm{C}]$ ) ou em nove seções (fig. 2), o que, também, privilegiaria mais seu centro onde consta um oval com o nome da Bíblia, inclusive em três estilos de letras caligráficas distintas, circundadas por uma ornamentação mais simples.

Figura 1: John Foster. Bíblia Pictórica da Família, Foster, 1890 [zoneamento 1]

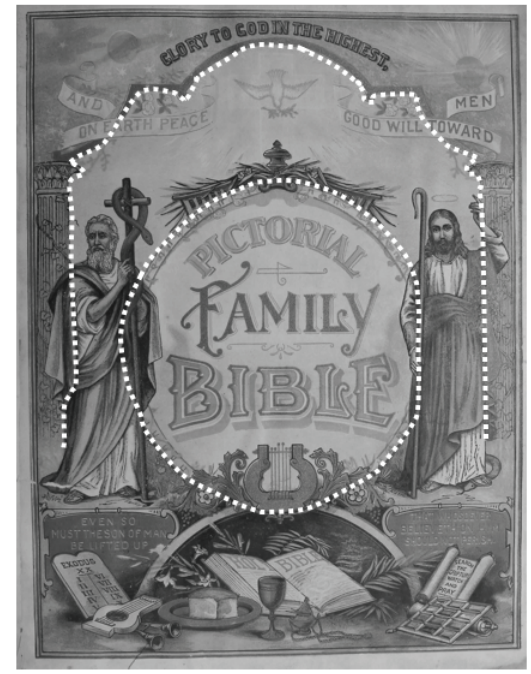

Figura 2: John Foster. Bíblia Pictórica da Família, Foster, 1890 [zoneamento 2]

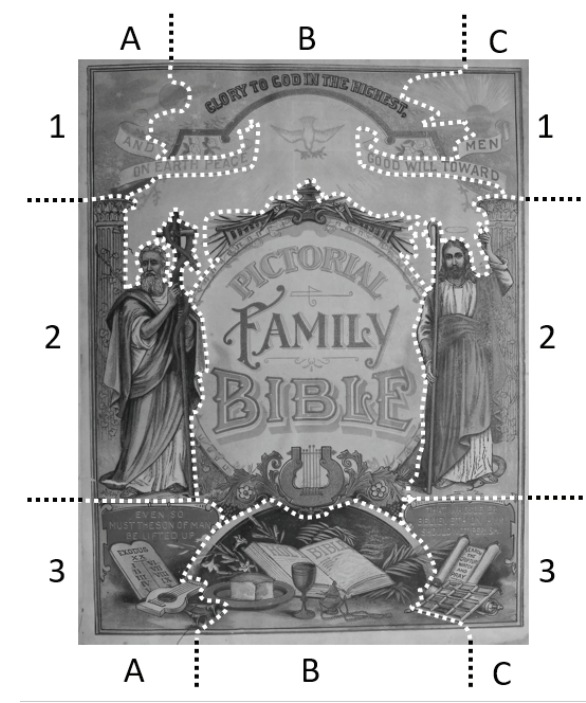

Fonte: Acervo do Museu de Memória Metodista

Um zoneamento bidimensional não é ideal, já que que nesta arte, aparece também um aspecto tridimensional: de cima para baixo, as bandeiras com textos estão em frente da parte superior da moldura (cf. as seções $1 \mathrm{~A}$ e 1C), as duas figuras, em frente das colunas (cf. as seções $2 \mathrm{~A}$ e $2 \mathrm{C}$ ) e alguns objetos menores (cf. as seções $3 \mathrm{~A}$ e $3 \mathrm{~B}$ ) em frente de um tipo de parede, 
compondo cinco níveis diferentes, formando um tipo de túnel ou cone que leva, "passando" os objetos, as paredes e as figuras e as colunas para chegar no título. Entretanto, como este aspecto tridimensional e o elemento composicional dos dois anéis (fig. 1) apontam como primeiro destaque a parte central da capa, o que zoneamento com nove campi (fig. 2) isso também favorece, ficamos com ela.

O que nos diz essa capa originalmente colorida então sobre a Bíblia? Já identificamos como elemento central com um fundo mais claro amarelado (cf. secção 2B) um tipo de brasão, circundado por uma borda, em sua parte maior decorada com leves elementos de ornamentação. Somente na sua parte superior há um destaque, formado por ramos e nove rosas vermelhas, com uma tonalidade levemente transparente. No centro dessa moldura há três palavras, - "Pictorial - Family - Bible" - que funcionam como um inscriptio, ou seja, um lema. Ao redor desse brasão destacam-se narrativas visuais ou uma pictura (cf. as seções 1A-1C, 2A e 2C, 3A-3C). Além disso, encontramse tanto acima como abaixo do brasão (cf. secções $1 \mathrm{~A}-1 \mathrm{C}$ e $3 \mathrm{~A}-3 \mathrm{C}$ ), narrativas textuais maiores e menores que podem ser entendidas como um tipo de subscriptio. Distribuídas de forma simétrica nas partes superior e inferiores, aparecem duas referências Bíblicas: os três elementos textuais na parte superior (cf. secções 1A,1B, 1C) citam Lucas 2.14 e, na parte inferior, cita-se João 3.14b-15a (cf. seção 3A e 3B). Ademais, as seções 3A, 3B e 3C contém ainda outros elementos textuais menores e não conectados entre elas. Classicamente, Inscriptio, pictura e subscriptio são conhecidos como elementos constitutivos de um emblema, um desenho literário desenvolvido no século 16 onde o conjunto dos três elementos formam um quebra-cabeça ou um enigma a ser resolvido pelo próprio leitor ou a própria observadora. Visto dessa forma, a capa apresenta um programa teológico-espiritual com uma proposta de uma práxis.

\section{O inscriptio}

Visto que sua centralização remete a sua importância na composição da capa, o brasão central nos diz de que se trata: de uma Pictorial Family Bible. Para cada palavra se usa uma cor, uma forma e um tamanho diferente. A palavra "Bíblia" é a maior, tem a cor mais vibrante - vermelho - que é somente repetida pelas nove rosas da moldura do brasão e mais seis rosas na parte superior. A palavra "família" é um pouco menor e tem uma cor que mais aparece e que corresponde a cor de muitos elementos estruturantes da capa. Já a palavra "pictorial" é menor ainda e sua tonalidade de um azul transparente 
somente aparece no fundo da capa no quinto nível. Dessa forma, a inscriptio apresenta três informações iconológicas, apontando de que se trata - de uma Bíblia -, a quem se dirige - famílias inteiras - e o que ela distingue de outras sua apropriação de elementos visuais. De uma forma sutil, mas, visível, somos convidados a considerar e desvendar o enigma visual da capa.

\section{A pictura}

A pictura é agrupada ao redor da inscriptio. A sua expressão mais "pura" - sem passagens textuais direitas - encontra-se ao lado esquerdo e direto da inscriptio. A esquerda, inspirada em Números 21.8, apresenta Moisés, segurando uma serpente posta em uma haste (cf. seção $2 \mathrm{~A}$ ). A cena sinaliza a possibilidade de cura, já que ele se refere, originalmente, a uma proposta de cura e a continuidade da vida para pessoas picadas por cobras. Ao lado direito do brasão, retrata-se Jesus (cf. secção 2C). Na sua mão direita ele segura um cajado o que o identifica como um pastor de ovelhas (cf. João 10.1-18). Mas, não se trata, unicamente, de uma referência à vida de Jesus e sua atuação durante a sua vida. Primeiro, há acima da sua cabeça uma auréola, o que sinaliza, especialmente na iconografia antiga, depois católica e ortodoxa, a pertença à esfera divina, sendo assim reservado para seguidores ou seguidoras de Jesus considerados exemplares, ou para a sagrada família. Originalmente, vem da iconografia do "Cristo Sol", como substituto do Deus Sol do fim do Império Romano até a época do imperador Constantino. Outro detalhe importante aqui é que Jesus pisa em uma serpente. Este gesto forte reserva a iconografia cristã, unicamente, para o Cristo ressurreto, sinalizando dessa forma a superação da morte e do mal, representados aqui pela serpente (cf. também Gn 3.15). Jesus aparece, então em uma dupla função: em uma missão terapêutica e salvífica. Ambas as figuras são retratadas sem menção às pessoas que fazem parte das narrativas originais. Em vez disso, aponta Moisés com a sua mão direita à serpente e Jesus com a mão esquerda na direção do céu enquanto eles estão olhando para o observador da capa (o olhar de Moises parece um pouco menos focado). Em distinção com pinturas como o programático Lei e Evangelho de Ernst Cranach, as duas referências têm o mesmo tamanho. A primeira é muito menos subordinada a outra. Dessa forma, em termos iconológicos, as duas figuras oferecem, visualmente, sanus como salus, sanidade e salvação, de uma forma mais igualitária, o que corresponde a uma inclusão simbólica da promoção da saúde como elemento essencial. Isso corresponde na época as ênfases de movimentos religiosos como o Exército da Salvação com o seu lema Soup, soap, and salvation [sopa, sabonete, salvação] ou o Evangelho Social. 
Na parte inferior aparecem ainda, nas suas extremidades: uma tábua com os números romanos de um a dez e a referência "Êxodo 20", uma lira e instrumentos de sopro (cf. seção 3A) e um pergaminho afirmando "Search the scripture watch and pray" - "procure nas escrituras, observe e ore". Neste lado, não se referencia um texto canônico, mas, uma atitude: observar no sentido de ver o texto, em vez de lê-lo ou escutá-lo. A isso corresponde uma paleta de tintas com doze compartimentos com cores primárias. Na parte central na seção 3B, encontramos uma Bíblia aberta, acima dela uma lira, ao lado esquerdo inferior dela um prato com um pedaço de pão, diretamente abaixo um cálice e algo que parece ser um recipiente para uma vela ou incenso que pode ser pendurado em três correntes. Em conjunto remetem a práticas litúrgicas da comunidade, como a leitura da palavra, a celebração e a celebração da Santa Ceia acompanhadas por música, envolvendo mais sentidos, no caso do olhar e do cheirar, descrevendo celebrações religiosas como experiências tocantes.

$\mathrm{Na}$ parte superior, encontram-se uma lua com estrelas (seção 1A), um sol, provavelmente nascendo (seção1C), e uma pomba descendo carregando um ramo, segundo a cor verde, recentemente apanhado (seção 1B). A sua volta há os contornos de uma cruz, de forma bem discreta com a tonalidade mais clara encontrada na capa. Novamente dominam referências à vida: a pomba com a folhagem cita a narrativa de Noé depois do dilúvio na esperança do recomeço da vida e a cruz iluminada sinaliza a luz da ressurreição, ou seja, a superação da morte. Já a lua e sol se referem tanto ao dia na sua totalidade quanto as esferas do mal e do bem e os mundos dos mortos e vivos; o que garantia a sua citação em muitas cenas de crucificação para demonstrar a abrangência e universalidade da obra salvífica de Cristo, por sua vez uma tradição que remete a uma narrativa de cuidado divino ininterrupto e abrangente para com o ser humano como, por exemplo, no Salmo 121. Mais uma vez, observamos que esta ênfase neste tipo de práxis, era especialmente assumida por movimentos religiosos que também nintegraram ao seu propósito a promoção do bem-estar e do bem comum, aquilo que Walter Rauschenbusch, líder do Evangelho Social, chamava de um avivamento social.

\section{O Subscriptio}

O "sub"- scriptio não se encontra mais somente abaixo da imagem, mas, igualmente, distribuído na parte superior (seções $1 \mathrm{~A}, 1 \mathrm{~B}, 1 \mathrm{C})$ e inferior $\left(3^{\mathrm{a}} \mathrm{e}\right.$ 3C). Na parte superior encontramos uma citação de Lucas 2.14, dividida em 
três partes: "Glory to God int the highest" [Glória a Deus nas alturas] (seção 1B), "And on Earth peace" [e paz na terra] (seção1A), "Good Will toward men" [boa vontade com a humanidade] (seção 2C). Parece que neste caso a estética da distribuição das palavras falou mais alto do que a preocupação com a lógica da frase, o que pode ser lido como preferência do visual sobre o textual. Iconologicamente falando, encontramos afirmações irênicas - paz na terra - e da boa-intencionalidade divina em relação a toda a humanidade. Isso acompanha a impressão geral de um "tom" benevolente dessa capa, já mencionada anteriormente. Na parte inferior, repete- se o modelo da distribuição de uma frase parcial em diversos lugares. Logo na frente de cada uma das figuras de Moisés e Jesus, aparecem duas pequenas paredes onde está escrita "even so must the son of man belifted up" (cf. seção 3A) [da mesma forma o filho do homem deve ser levantado] e "that whosoever believe thon him should not perish." [para que todo aquele que nele crê não pereça]. O texto maior de João 3.14 -18 - a capa somente cita 3.14b e 3.15a - tornou-se ponte de partia para três teorias da expiação, apresentadas por Pedro Abelardo (10791142 d.C.), o luterano Albrecht Ritschl (1822-1889 d.C.) e o metodista John Miley (1813-1895 d.C.), que focaram na cruz como visualização do amor de Deus para com o mundo. Ritschl era uma das inspirações para o movimento estadunidense do Evangelho Social que se estabelece a partir de 1870. John Miley contribuiu com elementos teológicos que levaram metodistas a se tornarem ativistas do movimento, até criar sua expressão máxima, o Credo Social da Igreja Metodista em 1908.

\section{As ilustrações e os artistas da Bíblia Ilustrada de Família de Foster}

Quando Foster apresenta a sua Bíblia de Família Ilustrada pela primeira vez em 1870, a primeira geração de norte-americanos já conhecia bem as obras desse tipo e, os metodistas, no mínimo tinham conhecimento dos respectivos esforços de Samuel Wesley 150 anos antes. A Bíblia de Foster, diferentemente do caso da Bíblia editada por Harper, não contratou um único artista, mas, Foster aproveitou obras de diversos artistas..$^{5}$ Mesmo assim, há uma clara preferência pelo gravurista francês Paul Gustave Doré (1832-1883) que contribuiu em treze das dezessete ilustrações da Bíblia, mesmo que sejam somente uma parte pequena das 800 ilustrações bíblicas criadas por ele.

Imagem 2: "Israelite women mourn with Jephthah daughter" [Mulheres israelitas choram com a filha de Jefté];

\footnotetext{
Imagem 5 - David feigning madness before Achish; imagem 6: David plays before Saul; imagem 11: The Maries at the sepulcher [até 1778, mas o estilo parece ser Pré-Rafaelita]; imagem 14: Jesus questioning the doctors.
} 
Imagem 3: "Samson's Death" [A morte de Sansão];

Imagem 4: "Banjamites carrying off" [Os benjamitas são carregados para fora];

Imagem 7: "Death of Saul" [A morte de Saul];

Imagem 8: "David punishing the Ammonites" [Davi punindo os amonitas];

Imagem 9: "Solomon and the queen of Sheba" [Salomão e a rainha de Sabá];

Imagem 12: "The nativity" Mt 11.11 [A natividade];

Imagem 13: "The stars in the east" Mt 11.2 [As estrelas no leste];

Imagem 15: "Christ in the synagogue" Mt 13.51 [Cristo na sinagoga];

Imagem 16: "The betrayal” [A traição];

Imagem 17: "The discent from the cross" [A retirada da cruz];

Imagem 18: "The death of Stephen" [A morte de Estevão];

Imagem 19: "Paul menaced by the Jews" At 21.2 [Paulo ameaçado pelos judeus].

Os temas escolhidos são de natureza dramática. A morte e o sofrimento dominam oito delas (imagens 1, 2, 4, 8, 16, 17, 18, 19). Podemos dizer que se trata de experiencias de limite. Mas, ao lado dessa ênfase "realista" da vida nua e crua, as gravuras revelam ainda outras preocupações. Primeiro, com a qualidade. Paul Gustave Doré (1832-1883) foi pintor e desenhista, além de ser o mais produtivo e bem-sucedido ilustrador francês de livros de meados do século XIX, um dos mais versáteis. Vista em conjunto, divide-se o seu trabalho em ilustrações de livros com um conteúdo fantástico da Bíblia, no caso de uma edição católica, a Vulgata (DORÉ, 1866), ${ }^{7}$ e sociais, como seus notáveis estudos da Comuna de Paris (DORÉ,1907) e das áreas pobres de Londres (DORÉ, 1872). Quando Foster opta em 1875 pelas ilustrações do artista Doré, ele já era uma celebridade com amplo reconhecimento nos EUA (e no Brasil ${ }^{8}$ ). A opção majoritária para um artista justamente famoso por trabalhar, paralelamente, temas religiosos e sociais, não consideramos um acaso, por corresponder, por um lado, com a iconologia da capa e, por outro lado, com o conteúdo do Termo de compromisso de temperança do qual trataremos na próxima seção.

Para conhecer a linguagem visual religiosa de Doré interpretamos, em seguida, uma das imagens escolhidas, "The descent from the Cross" [A retirada da cruz]. Encontramos na imagem sete pessoas, que podem ser divididas em três conjuntos diferentes: uma figura central, caracterizada pela linguagem corporal passiva, quatro pessoas mais próximas a esta figura central, inclusive

\footnotetext{
6 "Discent" significa, literalmente, decida, queda, etc. Nós optamos pelo costume de designação alemã que se refere a uma "Kreuzabnahme" ou "retirada da cruz".

7 Em uma pesquisa paralela confirmamos o uso preferencial de ilustrações de Doré na arte religioso divulgada nas escolhas dominicais entre 1880 e 1930, o que coincide com as datas de publicação das diversas edições da Bíblia de Foster a partir de 1875. O mesmo cremos que vai se repetir no estudo detalhada dos slides de lanternas usadas pelas Igrejas no Brasil.

$8{ }^{10}$ Muitas obras com ilustrações de Doré estão na Biblioteca Nacional do Brasil e isso em diversas edições, incluindo versões originais em francês e traduções para a língua portuguesa.
} 
com contato físico e, mais três outras pessoas que olham para a cena, porém sem estabelecer um contato direto com o corpo central. Expressivos nesta gravura são os gestos, especialmente das cabeças e das mãos. /

\section{Figura 3: Gustave Doré. A descida da cruz. In: Bíblia de Foster, 1890}

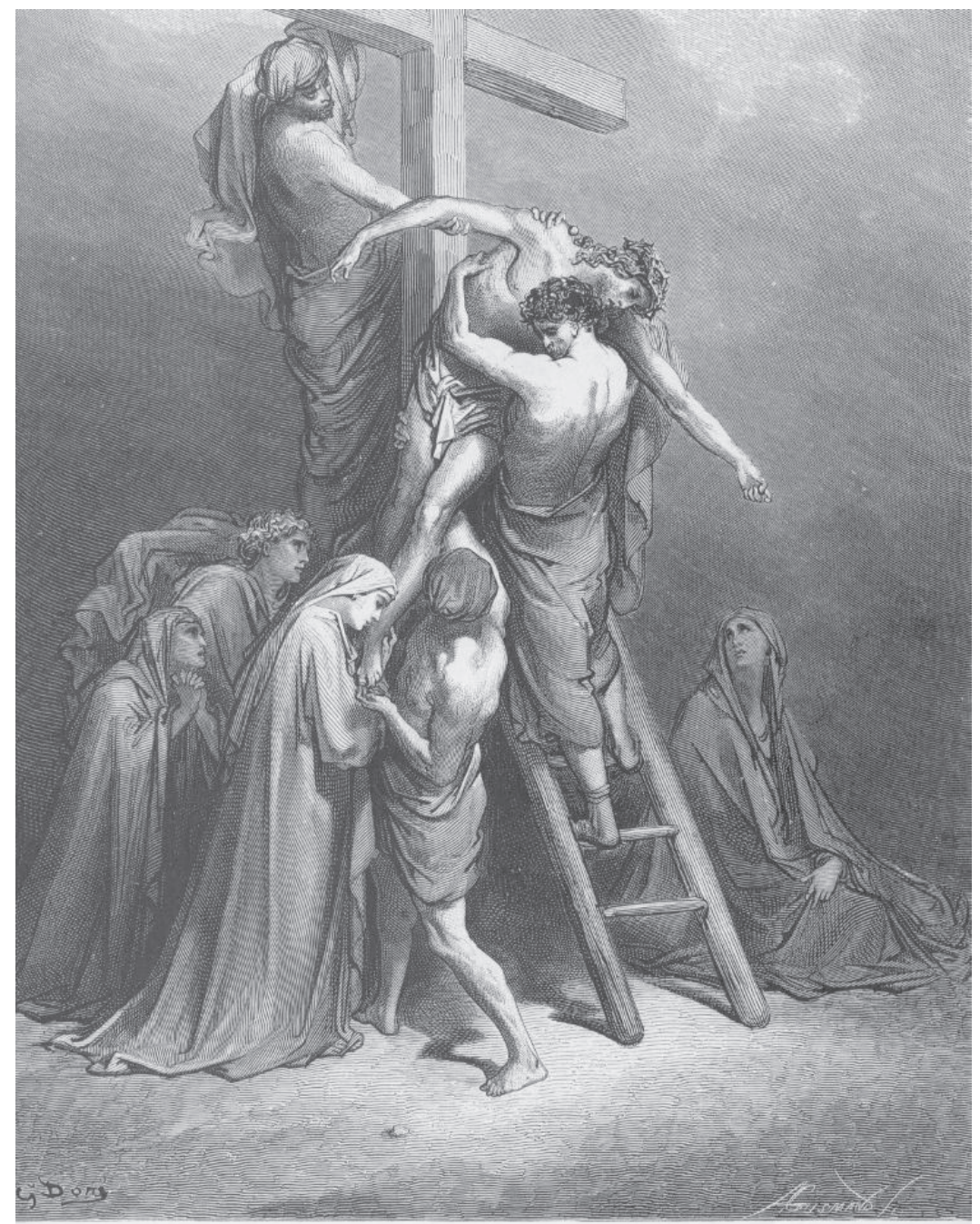

THE DESCENT FROM THE CROSS

Joseph of Arimathaea, an honourable counseller.... bought fine linen, and took him

down ... (Mark 15: 43, 46)

Fonte: Acervo Histórico da Igreja Metodista / Prédio Alfa; Umesp

A figura central seria Jesus, cuja expressão corporal é passiva, pois está morto. Enquanto ele é retirado da cruz, seu corpo remete a movimentos gerados por aqueles que o seguram. As personagens mais próximas a Jesus, 
expressam carinho, afeto e sensibilidade. Isso é verificável pelas mãos que seguram carinhosamente, que envolvem o corpo de Cristo sendo retirado com cuidado do madeiro. Os rostos das três figuras femininas parecem seguir uma iconografia de figuras femininas santas, cheio de dedicação, compaixão e afeto. Maria, no canto inferior direito, aparece como Mater Dolorosa, originalmente um motivo medieval, expressão visual máxima do sofrimento como Mitteiden, sofrer lado a lado de alguém, carregado de afeto e compaixão. Esta linguagem tem uma longa tradição na arte, que se inicia na arte renascentista e, se mantém, um elemento essencial dos estilos barroco e romântico, cujo último Doré combina com elementos do realismo. Assim, indicam a opção pelo artista Doré como pelas obras incluídas na Bíblia de Família Pictorial de Foster tanto uma articulação do afeto religioso, como de uma sensibilidade social. A linguagem visual romântica, ergo carregada de emoções e, ao mesmo tempo, realista, ergo não escondendo o sofrimento, explica o impacto dessas imagens, especialmente num século onde a morte estava muito mais próximo à população do que hoje, no mínimo, antes do covid 19.

O termo de compromisso de temperança da Bíblia Pictórica da Família de Foster: uma ênfase na ética pessoal e social

O terceiro elemento visual em nossa bíblia é o "Family temperance pledge [Juramento de temperança da família] que em nossa edição aparece em pretobranco (figura 4).

Figura 4: FOSTER, Charles. Pictorial

Family Bible, 1890. Detalhe: Family Temperance Pledge

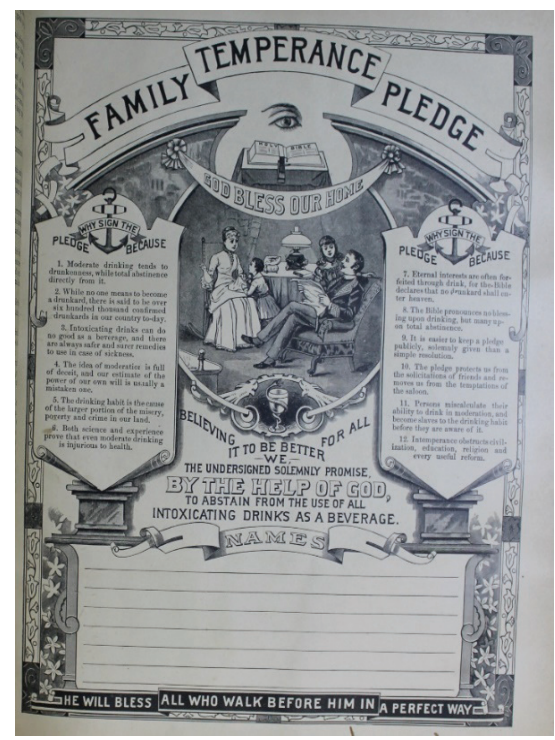

Fonte: Acerco da Igreja Metodista, São Paulo
Figura 5: Family Temperance Pledge, 1880.

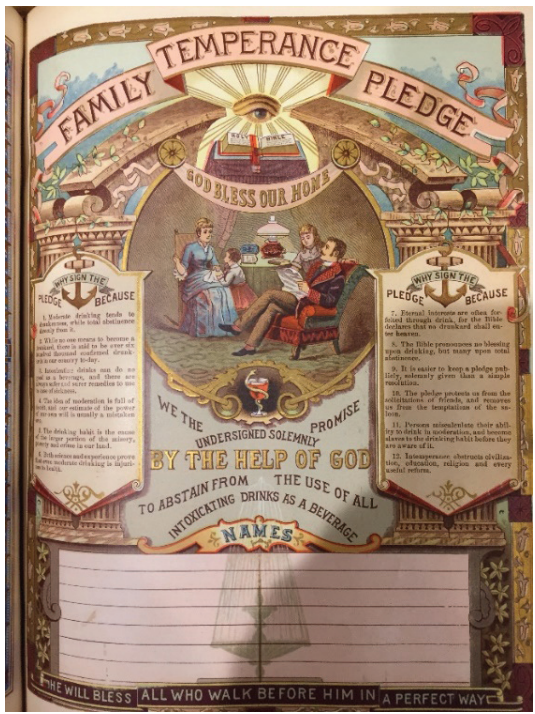

Fonte: South Gray Museum / Digital Collection 
A partir de 1880 ou 1882, o juramento foi incluído a diversas edições de Bíblias estadunidenses ${ }^{9}$ como, também, distribuído em folhas avulsas, inclusive de forma colorida (figura 5). "No verbete "Family temperance pledge", da Encyclopedia.com, comenta-se a relação entre o termo de juramento e as Bíblias [Ilustradas] da Família nos EUA:

Partia-se do princípio por todas as partes envolvidas nas campanhas de temperança que uma pessoa que fez o juramento, muitas vezes na presença de uma família com a Bíblia da família por perto, se submeteria a uma forte influência moral para manter a promessa. A Bíblia da família tinha um status icônico em todas as famílias cristãs do período.

Além disso, divulgaram também as escolas dominicais o termo junto as suas coletâneas da arte religiosa. ${ }^{11}$ Apesar do nome, promovia o termo não mais uma atitude temperante, ou o uso moderado de álcool, mas, a abstinência completa, que por sua vez se tornou uma marca moral da membresia das igrejas protestantes da missão e, posteriormente, de igrejas pentecostais com tal intensidade, que adquiriu um status de um tabu social, comprometendo almas e mentes.

No Brasil, o tabu sobreviveu, apesar de que se abandonou por completo a prática de assinar um termo. Enquanto a atitude de abstinência hoje é considerada uma expressão de um perfil religioso conservador, era o movimento até o fim do século 19 considerado progressista por ser promovido, muitas vezes, por mulheres abolicionistas e sufragistas (GIELE, 2016). ${ }^{12}$ A transição do modelo e temperança do século18 para o modelo da proibição correspondeu, também, à descoberta do alcoolismo como dependência química, física e emocional e ao seu enquadramento como doença e ameaça à saúde pública. A tragédia do movimento foi a transformação de uma preocupação social em um tabu social ${ }^{13}$. Seja o que for,

Por exemplo, também na Bíblia de Steward de 1882.

10 Houve também edições de Bíblias com folhas coloridas do FTJ como, por exemplo,da Bíblia de Steward. Confira: http://vitacollections.ca/southgreymuseum/2812287/page/6.

11 Por exemplo, fez um JTF parte da coletânea de 1915-1916 das Wilde's bible pictures que certamente foram usadas no Brasil entre 1890 e 1930.

12 Outro represente importante tanto do acento proibicionista como do Evangelho Social era o Bispo Canon Junior da Igreja Metodista Episcopal, Sul, um líder do movimento proibicionista. Ele presidiu a conferência central da Igreja Metodista Episcopal, Sul, no Brasil em 1932 e justificou a sua autonomia como igreja com a sua vocação de disseminar o "evangelho social” de Jesus (CANON, 1932).

13 A representante mais significativa e famosa dessa conjunção de projetos era uma leiga metodista, Frances E. Willard (1839-1898), cofundadora da Woman's Christian Temperance Union (WCTU) em 1874 e seu presidente entre 1879 e 1898 (WILLARD, 1889). Sua agenda contemplava o voto feminino, a abolição, a temperança, uma jornada diária de trabalho de no máximo oito horas, a reforma das prisões e a luta pelo ministério pastoral feminino (WILLARD, 1888). Como instrumento político ela abraçou a partir de 1885 o projeto do socialismo religioso segundo o modelo da Sociedade Fabiana britânica. Em tudo, era uma agenda bem próxima a itens centrais do movimento do evangelho social. 
o movimento de temperança era parte da vertente tradicional do movimento do Evangelho Social, composto por uma ala conservadora, uma ala reformista (que criou o Credo Social) e uma - pequena - ala revolucionária.

\section{A Bíblia de Família Pictórica, de Foster, e a Igreja Metodista Episcopal do Sul}

Destacamos na seção anterior que a Bíblia de Família Pictorial de Foster valoriza uma linguagem religiosa visual que estimula e interage com a afetividade humana, incluindo ela também uma sensibilidade social, usando elementos dos estilos do romantismo e realismo e algo tão clássico como a linguagem enigmática de emblemas, convidando para uma caminhada de descobertas. Esta segunda seção ousa, em seguida, a argumentar e defender que, tudo isso, não era somente um dos projetos espirituais dos EUA, mas, que se encontram interessantes correspondências nas missões das igrejas do sul dos EUA.

A Bíblia de Família Pictorial, de Foster, nasceu em Filadélfia, num território que pertencia durante a Guerra de Sessão (1872-1874) aos estados da união e não aos estados dos confederados, ou seja, ao chamado "sul". Que ela foi lida e trazida por pastores da Igreja Metodista Episcopal, Sul, para a missão acaba sendo - em razão desse fato - um dado importante. Devemos imaginar que isso fez parte de um movimento que estava "evangelizando" a mentalidado sulista com ideias do norte? Trata- de uma opção pessoal, valorizada na intimidade da família, sem pretensão de ser algo mais? De fato, não temos uma resposta a estas perguntas, porque nem sabemos quem de fato trouxe esse exemplar da bíblia para o Brasil. É relativamente seguro que fosse um americano ou uma americana, mas quem? Era um pastor - normalmente considerados mais conservadores? Era uma educadora - pessoas que no início do século 20 estudaram o evangelho social nos seus centros de treinamento, inclusive, do Sul ${ }^{14}$ ? Dessa forma, essa Bíblia deve ser considerada, ou uma alienígena em uma terra distante, ou um sinal entre outros que esse ambiente religioso não deve ser reduzido e interpretado a partir do antagonismo entre o norte progressista e o sul reacionário.

14 Verifique, por exemplo, a pesquisa de Ellen Blue (2011) em relação a mulheres sulistas, diáconas e educadoras, que desafia diversas convicções acadêmicas supostamente "consagradas": primeiro, que social gospel era um movimento predominantemente de homens, segundo, que ele morreu ao redor do fim da I. Guerra Mundial e, terceiro, que ele nunca chegou no sul. 
Um elemento central da nossa argumentação é surpreendentemente uma opção doutrinária que se tornou canônica nas missões latinas da Igreja Metodista Episcopal, Sul, a partir de 1888. Neste ano, modificou-se um meioversículo do Segundo Artigo da Religião que faz parte do núcleo doutrinário duro dessa denominação. Desde então, afirma-se que "[...] Cristo, verdadeiro Deus e verdadeiro Homem, [...] realmente sofreu, foi crucificado, morto e sepultado, para nos reconciliar com seu Pai," substituindo "para reconciliar seu Pai conosco". O argumento detalhado a respeito pode ser acompanhado em Renders (2013, p. 25-51); aqui somente sintetizamos os seus resultados mais importantes. Primeiro, precisa-se entender o aspecto técnico-jurídico dessa alteração. Trata-se de uma modificação única na história do metodismo episcopal, já que atualizações dos artigos da religião eram estritamente proibidas. Os tradutores dos Cânones sempre tinham de assinar que eles não alteram a parte considerada constitutiva, em especial, os artigos da religião o que, aliais, consta também nos cânones com as alterações, mantidas até hoje em dia. Que essa mudança ocorreu inicialmente, digamos, de forma despercebida, e depois foi mantida não é provável. Pelo contrário, a mudança representa uma consciente reorientação teológica. Trata-se da transição de uma teologia da cruz que exige o sacrifício para uma teologia da cruz que detecta como seu centro o amor divino incondicional para com o cosmo. É uma expressão nova da posição de Pedro Abelardo contra Anselmo de Cantuária, relida pelo luterano Albrecht Ritschl (1822-1889) $)^{15}$ e pelo metodista estadunidense John Miley (1813-1895), porém, sob consideração maior de Hugo Grotius. ${ }^{16}$ No seu centro, é sua renovada compreensão da mensagem da reconciliação como um evento-processo de superação da inimizade humana pela amizade divina ${ }^{17}$ o que acabou sendo uma das ênfases soteriológicas do movimento do Social

15 Albrecht Ritschl (1850, p. 83) e (1900, p. 473-475): “A justiça de Deus [...] na sua essência é idêntica à sua graça [...]. Não é bíblico supor que qualquer um dos sacrifícios do Antigo Testamento, fundamento da analogia segundo a morte de Cristo deveria ser julgado, teria tido o significado de mover Deus da ira para a graça [...]. Não é bíblico supor que a oferta de sacrifício em si inclui um ato penal, executado não sobre o culpado, mas em cima da vítima, que toma seu lugar. A representação por sacerdote e sacramento não tem como objetivo qualquer sentido exclusivo, mas inclusivo".

16 Anota a proximidade dos anos de surgimento das obras de Miley (1879; 1892 [vol. 2], p. 107, 122-123, 133-154) à época discutida. As ideias centrais em relação ao nosso tema já aparecem na sua obra Atonement in Christ (1879) [A expiação em Cristo] onde ele rejeita tanto a ideia da substituição penal de Calvino como da teoria do exemplo moral de Abelardo.

17 Detalhes cf. em RENDERS, 2017, p. 465-491. 
Gospel ou do Evangelho Social. ${ }^{18} \mathrm{Um}$ grupo dos metodistas estadunidenses já tinham assimilados as ideias de Miley, quando Ritschl chegou via Rauschenbusch nos EUA a partir de 1907. O eco mais durador dessa alteração podemos ver ao longo do século 20 pela valorização do Credo Social na Igreja Metodista do Brasil a partir de 1908, na Igreja Metodista Episcopal, Sul, de 1918. A preparação para essa mudança requer múltiplas ferramentas, entre as quais a Bíblia de Familia Pictórica de Foster, com a sua mensagem específica, era somente uma indicação, mas, uma que de repente se comunicou bem com as características da sua linguagem visual do afeto e da sensibilidade social. Como segunda data, depois de 1888 , da crescente consumação da integração dessa vertente religiosa no metodismo brasileiro, citamos ainda um pronunciamento significativo ocorrido nas seções administrativas - e públicas - da autonomia da Igreja Metodista em 1930. Cita-se, nas atas do concílio geral, um posicionamento do bispo estadunidense Cannon, Jr., justamente, o líder religioso do movimento da proibição nos EUA: ${ }^{19}$

O Bispo James Cannon Junior fez um discurso sobre este tema: "Igreja e o Evangelho Social" explicando os princípios fundamentais das atividades da Igreja, expôs cuidadosamente a diferença entre apelo direto do Evangelho a cada alma individualmente e a relação necessária de cada indivíduo para com a sociedade, desde que ele aceita os ensinamentos de Jesus Cristo como Mestre e Senhor. Estes ensinamentos de Jesus estão claros nas declarações a seus discípulos - "Vós sois a luz do mundo" "Vós sois o sal da terra". [...] e na sua aplicação devem se dirigidos pela lei do amor fraternal: "Amarás ao teu próximo como a ti mesmo." Este princípio de fraternidade humana [...] deve finalmente transformar a sociedade humana inteira. Este princípio deve ser aplicado em todas as relações industriais, internacionais e sociais. [...] O Bispo declarou que é de fato muito importante e significativo que na primeira reunião pública sob a direção do seu Concílio Geral [...], a Igreja Methodista do Brasil mostrasse enfaticamente sua atitude para com o Evangelho social de Jesus, colocando-se assim em linha de frente com o Metodismo desde os dias de Wesley. (IGREJA METHODISTA DO BRASIL, 1930: 40). (grifo do autor).

Assim, marcam a alteração do Segundo Artigo da Religião em 1888 e o pronunciamento de 1930 no Concílio Geral Da Igreja Metodista do Sul, missão brasileira, dois polos da crescente abertura institucional para

18 O "Social Gospel” não deve ser confundido com seu primo linguístico, o "movimento gospel”. Ambos representam formas do avivalismo militante, mas somente o primeiro opera com conceitos como "pecado social", "profetismo como denúncia da injustiça" ou a virtude do "favorecimento dos/as menos/as favorecidos/as"

19 Em1930, Cannon, Jr., estava no auge da sua importância nacional estadunidense. Ainda no mesmo ano, começaria uma investigação contra ele que levaria o movimento da proibição nos EUA ao descrédito e a falência. Apesar disso, as acusações levantadas contra ele, tanto por cortes cíveis como seculares, não resultaram em uma condenação. 
tendências de inter-relacionar sanus e salus a promoção da vida em nível pessoal e público. A mudança do artigo da religião e formulação do Credo Social representam seus núcleos duros, tanto em termos doutrinários como práticos; a Bíblia de Família Pictorial de Foster documenta a o aspeto e o interesse devocional do movimento.

\section{A Bíblia de Família Pictorial, de Foster, como instrumento para praticar uma piedade do avivamento social}

Além da contextualização histórico-teológica, precisamos, por último, voltar para o nosso exemplar da Bíblia de Família Pictorial de Foster para destacar que não se trata somente de uma expressão de um movimento, mas, que se expressa aqui também que o movimento era vivenciado e energizado por uma espiritualidade. Além da necessária "Teologia do Evangelho Social”, escrita por Walter Rauschenbusch em 1917 e recentemente traduzida para a língua portuguesa (RAUSCHENBUSCH, 2019), o movimento cultivava e promovia também uma práxis pietatis a qual o própria Rauschenbusch contribuiu com uma coletânea de orações intitulada For God and the people: prayers for the social awakening (1909) [Para Deus e o povo: orações para o avivamento social], traduzidas, aliás, como Preces fraternais pela Confederação Evangélica Brasileira em 1937. A Bíblia de Família Pictorial de Foster parece-se alinhar a esse esforço, sua vez empregando a cultura visual religiosa. Isso desafia, parcialmente, categorias classicamente aplicadas ao Evangelho Social, como, por exemplo, "expressão da teologia liberal europeia". Apesar de detectar influências importantes do movimento, como a relação entre Ritschl e Rauschenbusch demonstra, mas, não se considera suficientemente que a militância social nos EUA e na Europa tem também outras fontes, inspirações e expressões do que o liberalismo teológico europeu. Pensadores como o teólogo metodista Miley partiram do "pensamento arminiano, empregando a livre agência humana como princípio estruturante" (BAUMART, 2006, p. 179). Baseada no caráter universal da graça redentora falava-se da responsabilidade humana em nível pessoal e pública. Metodistas não abraçaram seu Credo Social por ser, digamos, bem temperado, burguês e liberal, mas, porque eles o entenderem como extensão da sua militância de santidade ao setor público. A partir das polarizações depois da II Guerra Mundial que marcaram e demarcam tanto o protestantismo e o pentecostalismo brasileiro, criaram-se narrativas sobre o caráter do protestantismo (e pentecostalismo) brasileiro que focam mais nas também existentes antecipações dos seus violentos conflitos do que nas narrativas alternativas que, paralelamente, fizeram parte desse protestantismo brasileiro. Um elemento dessas narrativas alternativas que levaram a militância social era uma piedade da palavra e da práxis da fé; e bíblias como a Bíblia de Família Pictorial de Foster tinham o 
propósito de promover afeto religioso e sensibilidade social como catalizadores de transformações maiores.

\section{Considerações finais}

Partimos da análise da linguagem visual religiosa da Pictorial Family Bible, de Foster, que, provavelmente, acompanhava um missionário metodista e a sua família entre o fim do século 19 e o início do século 20 para o campo missionário no Brasil. Demonstramos uma significativa convergência da sua teologia visual com movimentos sociais da sua época, em especial, com o chamado Social Gospel. Argumentamos que essa opção não era tão singular no metodismo brasileiro como se eventualmente hoje imagina e afirma. Propomos uma visão mais diversificada do protestantismo brasileiro entre os últimos vintes anos do século 19 e primeiros trinta anos do século 20, inclusive, do próprio movimento do Evangelho Social que, hospedava, uma ala conservadora, uma ala reformadora e uma - pequena - ala revolucionária. O exemplar da Bíblia de Familia Pictorial de Foster, encontrada no acervo da Igreja Metodista, é somente uma peça no puzzle da [re]descoberta de um protestantismo brasileiro mais diversificado e "colorido" do que, aparentemente, se costuma imaginar.

\section{Referências bibliográficas}

BLUE, Ellen. St. Mark's and the Social Gospel: Methodist Women and Civil Rights in New Orleans, 1895-1965. Knoxville: University of Tennessee Press, 2011.

BUSCHART, W. David. Exploring Protestant traditions: an invitation to theological hospitality. Downers Grove, Illinois: InterVarsity Academic, 2006.

DORÉ, Gustave. A Bíblia em folhas soltas. [Rio de Janeiro]: Ed. Brasil-América Ltda, [1976?]. DORÉ, Gustave; JERROLD, Blanchard. London: a pilgrimage, [s/e] 1872.

DORÉ, Gustave. Versailles et Paris en 1871 d'après les dessins originaux de Gustave Doré. Prefácio de M. Gabriel Hanotaux. Paris: Plon-Nourrit et cie, 1907.

FOSTER, Charles. Pictorial Family Bible. Filadélfia, Pen: Andrew J. Holman \& Co, 1890.

GIELE, Janet Zollinger. Two paths to women's equality: temperance, suffrage and the origins of modern feminism. Chicago: University of Chicago Press, 1996

MILEY, John. The atonement in Christ. New York: Philipp and Hunt, 1879.

MILEY, John. Systematic Theology. 2 vols. New York; Cincinnati: Hunt \& Eaton; Cranston \& Stowe, 1894, p. 2:107, 122-23, 133-54.

RENDERS, Helmut. As bíblias da família ilustradas do século 19 e o surgimento da cultura visual no protestantismo estadunidense e da missão. Plura - Revista de História da Religião, Juiz de Fora, v. 9, n. 2, p. 100-127, jul./dez. 2018. 
RENDERS, Helmut. "To reconcile us to his Father": a unique translation of the 2nd Article of Religion of the Methodist Church in Brazil and three other lusophone countries. Methodist Review, New York, v. 5, p. 25-51, jan./dez. 2013.

RENDERS, Helmut. Reconciliação como "superação de inimizade pela amizade": desenvolvimento e desdobramentos brasileiros de uma ênfase soteriológica metodista. Pistis \& Praxis, Curitiba, v. 9, n. 2, p. 465-491, abr./ago. 2017.

RENDERS, Helmut. Uma proposta de periodização da cultura visual evangélica brasileira: surgimento, abrasileiramento e metaformização glocal. Numen, Juiz de Fora, v. 21, n. 1, p. 10-37, jan./jun. 2018.

RITSCHL, Benjamin Albrecht. Die christliche Lehre von der Rechtfertigung und Versöhnung: Die Geschichte der Lehre. Vol. 1. Bonn: Adolph Marcus, 1900. [Tradução do título principal: O ensino cristão da justificação e redenção: a história da doutrina].

RITSCHL, Benjamin Albrecht. Die Entstehung der altkatholischen Kirche. Bonn: Adolph Marcus, 1850. [Tradução do título principal: O surgimento da Igreja Católica Antiga]

S. N. "Family Temperance Pledge". In: Encyclopedia.com. Oxford University Press; Columbia University Press; CENGAGE, 2019. Disponível em: < https://www.encyclopedia.com/ social-sciences/applied-and-social-sciences-magazines/family-temperance-pledge $>$. Acesso em: 29 set. 2019.

WESLEY, Samuel. The history of the Old and New Testament attempted in verse and adorn'd with three bundred \& thirty sculptures. The cuts done by John Sturt. London: Printed for John Hocke. 1716.

WESLEY, Samuel. The history of the Holy Bible: from the revolt of the ten tribes to the end of the prophets. with sculptures, Printed for John Hocke. [London][170?].

WESLEY, Samuel. The bistory of the New Testament attempted in verse and adorn'd with one bundred \& fifty two sculptures. The cuts done by John Sturt. London: For Charles Harper, 1701.

WILDE, W.A. List of the Wilde Bible pictures. Boston: W. A. Wilde Company [191?]. Disponível em: < https://archive.org/details/listofwildebible00wawi >. Acesso em: 4 set. 2019.

WILDE, W. A. Wilde's Bible Pictures: beautiful and exact half-tone reproductions from photographs and steel engravings for use in the Sunday School and the Home (classic reprint). London: Forgotten Books, 2018.

\section{Referências iconográficas}

Figuras 1-4 e Anexo 1: FOSTER, Charles. Pictorial Family Bible. Filadélfia, Pensilvânia: Andrew J. Holman \& Co, 1890. [Exemplar do Centro de Memória Metodista, Escola de Teologia, Universidade Metodista de São Paulo]

Figura 5: Stewart Family Bible, 1880, Family Temperance Pledge. In: South Gray Museum / Digital Collection. Disponível em: <http://vitacollections.ca/southgreymuseum /2812287/ page/6>. Acesso em: 4 set. 2019.

Submetido em: 23-4-2020

Aceito em: 21-9-2020 


\section{Anexo 1: “Capa”}

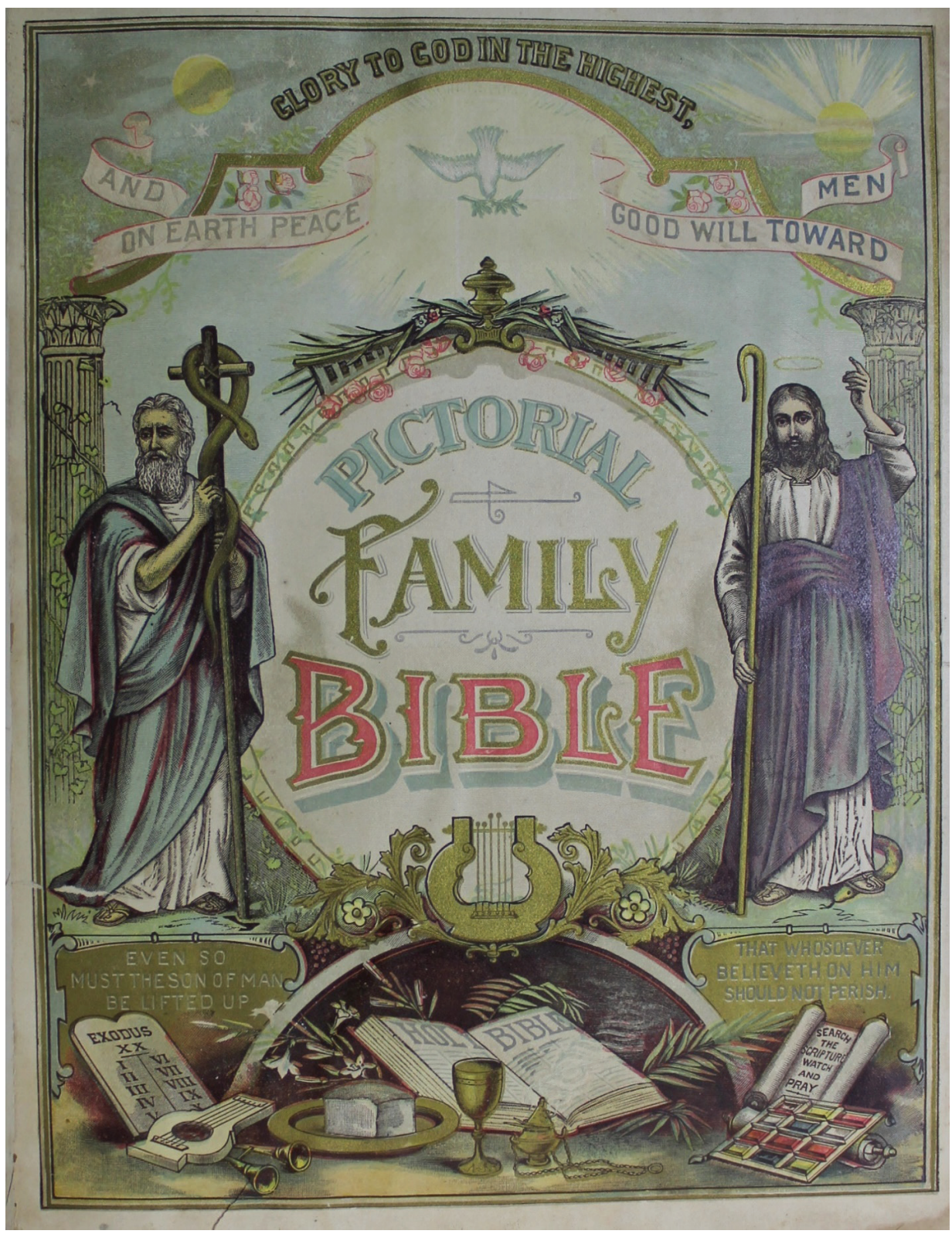

